\title{
Determination of The Level of Knowledge About Hpv Among Adolescents and Improvement of Vaccinationapproval Through Health Education In The Area of Trikala, Central Greece
}

loannis Thanasas ( $\square$ thanasasg@hotmail.com )

General Hosptal of Trikala

Giagkos Lavranos

Medical School and Department of Health Sciences, European University of Cyprus, Nikosia Cyprus

Penelopi Gkogkou

Clinical Oncology Department, Norfolk and Norwich University Hospital, United Kingdom

Dimitrios Paraskevis

Department of Hygiene Epidemiology and Medical Statistics, Medical Shcool, National and Kapodistrian University of Athens, Athens Greece

\section{Research article}

Keywords: HPV, HPV vaccines, teenagers, Health Education, Central Greece

Posted Date: October 14th, 2020

DOI: https://doi.org/10.21203/rs.3.rs-60046/v1

License: (c) (1) This work is licensed under a Creative Commons Attribution 4.0 International License.

Read Full License 


\section{Abstract}

Background: The aim of this study is to assess the importance of the role of the Health Education among young adolescents, regarding the level of knowledge about the HPV and the acceptance of the HPV vaccination, in order to increase the vaccination coverage, both in young adolescents and young teenagers in the area of Trikala, in Central Greece.

Methods: The methodological tools of the study were questionnaires. The completion of the questionnaires was gained after the informed and written consent of the parents - guardians. Ethical approval was obtained of the Ministry of Education, Research and Religions. Students of the 1st Gymnasium, randomly chosen by drawing among all school groups of the area. In the first phase of the study, the questionnaires were completed by the entire study population. During the second and third phases, the completion of the questionnaires concerned the population under study, immediately after the interactive seminar and three months later, respectively. The IBM SPSS 20.0 statistical program was used for analyzing the data and extracting the results.

Results: A total of 434 female students, who met the criteria for participation in the study, completed the questionnaire (response rate $76.26 \%$ ). Most participants (66.6\%) were girls. From the final analysis of the results we observed a rapid change in the level of awareness about the HPV virus, between the three phases of the study. The percentage of the participants who stated that they "do not know" what HPV is, decreased from $44.4 \%$, before the informative interactive intervention in students (first phase), to $1.6 \%$ and 8.1\%immediately after the intervention (second phase) and 3 months later (third phase), respectively. Similarly, the willingness of young students to be vaccinated against the HPV was increased from $71 \%$ during the first phase of the study, to $89.1 \%$ and $83.5 \%$ after the second and third phases, respectively.

Conclusion: Young teens are poorly informed about the HPV and HPV vaccination. However, with the use of targeted interactive informational interventions in the school environment, a statistically significant increase in both the level of knowledge about the HPV and the infection caused by it, is recorded, as well as in the willingness of young adolescent students to be vaccinated against the cervical cancer.

\section{Background}

The Human Papillomavirus (HPV) is currently the leading cause of cervical cancer. Intraepithelial cervical lesions and cervical carcinomas which are associated with persistent infection from high - risk HPV genotypes, are considered to be responsible for more than $99 \%$ of cervical cancers [1]. It is currently estimated that about 529.800 new cases of cervical cancer are diagnosed annually, with a mortality rate of about $50 \%$ [2,3]. Cervical cancer is the fourth most common type of cancer among women worldwide. The greatest incidence concerns the less developed countries, where the lack of resources and infrastructure is estimated to significantly oppose the establishment and implementation of preventive programs [4]. 
The indisputable finding of a causal link between the HPV and cervical cancer has led the scientific community to the decision to create HPV vaccines, the availability of which has completely changed the scientific data on the primary prevention of cervical cancer. In 2006, the quadrivalent vaccine (Gardasil®) was first released, and a year later the bivalent one (Cervarix $\left.{ }^{\circledR}\right)$ was approved for circulation. Most recently in 2014, the nine-valent vaccine against HPV (Gardasil $9 \circledR$ ) was released. Given the proven effectiveness, cost - effectiveness ratio and safety of the HPV vaccines nowadays, the global vaccination of young adolescents against HPV and cervical cancer should be a public health priority [5, $6]$.

In Europe, the HPV vaccination program has been adopted by the majority of the Member States of the European Union [7]. In 2010 it was estimated that the vaccination coverage of the population, ranged between $17 \%$ and $81 \%$. Specifically, in France, Luxembourg and Norway the vaccination coverage rate was between $17 \%$ and $30 \%$, in Denmark and Italy it ranged from $56-58 \%$, while in Portugal and the United Kingdom it was between $80 \%$ and $81 \%$ [8]. Based on the latest data, it is estimated that in France nowadays, the vaccination coverage of the 16years-old adolescents still remains low (19\%). In the United Kingdom and Spain it is estimated to be over $80 \%$, while in the United States and Germany the rates are lower, ranging between $40 \%$ and $50 \%$ [9]. The vaccination coverage of Greek adolescents during the period $2008-2014$ was only $8.9 \%$, increasing from $3.2 \%$ in 2008 to $17.1 \%$ in 2011 . However, it was decreased to $2.1 \%$ in 2012 , reaching $9.2 \%$ and $11.5 \%$ in 2013 and 2014 respectively [10].

According to the World Health Organization [11] declaration and the outcomes of numerous research studies, the target population of the HPV vaccination should be the young adolescent students, in Primary and Secondary Education $[12,13,14]$.

The aim of this study is to investigate whether the role of the Health Education could possibly enhance the awareness among young adolescents regarding the HPV, as well as in the acceptance of the HPV vaccination. The scope in the end of this study is to increase the vaccination coverage in both young adolescents and young teenagers.

\section{Methods}

\section{Study Sample}

The study involved first - grade Gymnasium students, who lived in the city, towns and villages in the Prefecture of Trikala, in Central Greece. The basic condition for their participation was that the participants should be students of the 1st Grade. The Ethical approval to conduct this research was obtained after the submission and approval of the protocol from the Institute of Educational Policy of the Ministry of Education, Research and Religions (Ministerial Decision No. 219048/ $\Delta 2 / 19-12$ - 2018). As a part of the ethical approval for the participation of the students in the research study, was the written and signed consent of their parents and/or guardians, after being adequately informed. The anonymity and confidentiality of participants data throughout the research process, was ensured from the study 
protocol. The study included students from seven school complexes in the Prefecture of Trikala, distributed as follows: four schools selected from the city of Trikala (urban school complexes), two schools from the province of Kalambaka in the Prefecture of Trikala (rural school complexes) and the only private school existing in the prefecture. Out of 573 questionnaires given to students, 136 returned uncompleted (76.26\% response rate). The largest response was observed in the Private High School (95\%), while the 4thGymnasium of Trikala and the 1st Gymnasium of Kalampaka were those with the lowest participation rates, $68.1 \%$ and $68.1 \%$, respectively (Table 1 ).

Table 1

Response rate of the students of the 1 st Grade of the school groups that were included in the study.

\begin{tabular}{|llll|}
\hline School Unit & Study Population & Specimen & Percentage \\
\hline $1^{\circ}$ Gymnasium of Trikala & Intervention group & $95 / 119$ & $79.8 \%$ \\
\hline $4^{\circ}$ Gymnasium of Trikala & Control group & $62 / 91$ & $68.1 \%$ \\
\hline $3^{\circ}$ Gymnasium of Trikala & Intervention group & $80 / 98$ & $81.6 \%$ \\
\hline $9^{\circ}$ Gymnasium of Trikala & Control group & $47 / 65$ & $72.3 \%$ \\
\hline $1^{\circ}$ Gymnasium of Kalampaka & Intervention group & $45 / 66$ & $68.1 \%$ \\
\hline $2^{\circ}$ Gymnasium of Kalampaka & Control group & $51 / 74$ & $68.9 \%$ \\
\hline Private Gymnasium & Intervention and Control group & $57 / 60$ & $95 \%$ \\
\hline
\end{tabular}

The four urban school complexes were categorized into two groups (2schools in each group): one school was the interventional sample of the studied population and the other, in the same area of the city, was the control one (not the interventional sample of the studied population). Concerning the urban school group, the first - grade students of the 1st and 3rd Gymnasium of Trikala, constituted the studied interventional population. The 4th and the 9th Gymnasium of Trikala were the control sample of the studied population. The selection of the school complexes that constituted the studied interventional population was made randomly by drawing lots. Similarly, in the rural school groupof the province of Kalambaka, the 1st Gymnasium of Kalampaka was the sample of intervention and the 2nd Gymnasium of Kalampaka was the sample of control of the studied population. Regarding, the Private Gymnasium, half of the 1st Grade students constituted the interventional sample and the other half were the noninterventional one (control sample) of the studied population (Table 2). 
Table 2

Categorization of school complexes that included in the study and actions throughout the research process.

\begin{tabular}{|c|c|c|c|}
\hline Phases & School Unit & Study Population & Actions \\
\hline \multirow[t]{7}{*}{ Phase I } & $\begin{array}{l}1^{\circ} \mathrm{Gymnasium} \text { of } \\
\text { Trikala }\end{array}$ & Intervention group & Completion of a questionnaire \\
\hline & $\begin{array}{l}4^{\circ} \text { Gymnasium of } \\
\text { Trikala }\end{array}$ & Control group & Completion of a questionnaire \\
\hline & $\begin{array}{l}3^{\circ} \mathrm{Gymnasium} \text { of } \\
\text { Trikala }\end{array}$ & Intervention group & Completion of a questionnaire \\
\hline & $\begin{array}{l}9^{\circ} \mathrm{Gymnasium} \text { of } \\
\text { Trikala }\end{array}$ & Control group & Completion of a questionnaire \\
\hline & $\begin{array}{l}1^{\circ} \mathrm{Gymnasium} \text { of } \\
\text { Kalampaka }\end{array}$ & Intervention group & Completion of a questionnaire \\
\hline & $\begin{array}{l}2^{\circ} \text { Gymnasium of } \\
\text { Kalampaka }\end{array}$ & Control group & Completion of a questionnaire \\
\hline & Private Gymnasium & $\begin{array}{l}\text { Intervention and } \\
\text { Control group }\end{array}$ & Completion of a questionnaire \\
\hline \multirow[t]{4}{*}{$\begin{array}{l}\text { Phase } \\
\text { II }\end{array}$} & $\begin{array}{l}1^{\circ} \mathrm{Gymnasium} \text { of } \\
\text { Trikala }\end{array}$ & Intervention group & $\begin{array}{l}\text { Seminar } \& \text { completion of the same } \\
\text { questionnaire }\end{array}$ \\
\hline & $\begin{array}{l}3^{\circ} \text { Gymnasium of } \\
\text { Trikala }\end{array}$ & Intervention group & $\begin{array}{l}\text { Seminar } \& \text { completion of the same } \\
\text { questionnaire }\end{array}$ \\
\hline & $\begin{array}{l}1^{\circ} \text { Gymnasium of } \\
\text { Kalampaka }\end{array}$ & Intervention group & $\begin{array}{l}\text { Seminar \& completion of the same } \\
\text { questionnaire }\end{array}$ \\
\hline & Private Gymnasium & Intervention group & $\begin{array}{l}\text { Seminar \& completion of the same } \\
\text { questionnaire }\end{array}$ \\
\hline \multirow[t]{4}{*}{$\begin{array}{l}\text { Phase } \\
\text { III }\end{array}$} & $\begin{array}{l}1^{\circ} \mathrm{Gymnasium} \text { of } \\
\text { Trikala }\end{array}$ & Intervention group & Completion of the same questionnaire \\
\hline & $\begin{array}{l}3^{\circ} \mathrm{Gymnasium} \text { of } \\
\text { Trikala }\end{array}$ & Intervention group & Completion of the same questionnaire \\
\hline & $\begin{array}{l}1^{\circ} \mathrm{Gymnasium} \text { of } \\
\text { Kalampaka }\end{array}$ & Intervention group & Completion of the same questionnaire \\
\hline & Private Gymnasium & Intervention group & Completion of the same questionnaire \\
\hline
\end{tabular}

\section{Questionnaire of the Study}

The methodological tool of the study was a questionnaire. The questionnaire was chosen after a systematic bibliographic review of studies, with a similar research question. The questionnaire has been 
previously published and the license to use it was obtained after contacting the editorial team [15]. The editorial team approved the use of the English - language questionnaire. Subsequently, it was translated into Greek by two researchers, with an excellent knowledge of the English language and relevant knowledge of HPV vaccines and health education. Adopting the questionnaire in Greek Health Educational System some questions were removed while others were added. In order to test the clarity of the questions, a preliminary survey was initially conducted, based on the results of which the validity was fully checked and then the questionnaire received its final form.

Criteria for selecting the questionnaire of the study were the limited possible number of questions and the focus on topics related to the HPV, HPV vaccination and cervical cancer. Its final form consisted of 52 closed - ended questions, which were divided into four main sections. In the first and second sections were included school data and student demographics, respectively. The third section included students' knowledge, attitude, and behavior toward HPV infection and the awareness of the relationship between the virus and cervical cancer. The fourth section included students' knowledge, attitude, and behavior toward HPV vaccination and cervical cancer. The data collected from the questionnaire were anonymized. No personal data was collected.

\section{Study Schedule}

The survey was conducted during the academic year 2018-2019. The time period for the study was from January 2019 to May of the same year. The completion of the questionnaires and the informational lectures to the students, were taking place during the working days and hours. The duration of the students' briefing did not exceed forty - five minutes - that is of, - one teaching hour. The research was divided into three phases (Table 2). During the first phase, the questionnaire was completed by the entire study population (intervention group and control group). Two weeks later (second phase), the information of the students included in the studied interventional population have been taken place, concerning the HPV and the value of the vaccination against it. The informational lectures that took place in the school amphitheater included the electronic presentation of the knowledge about the HPV, the HPV vaccination and their importance nowadays. The completion of the questionnaire by the students who constituted the studied interventional population, took place at the end of the seminar. Three months after the end of the seminars, the study was accomplished with the completion of the questionnaire, for the third time (third phase), by the students of the interventional group.

\section{Data collection}

The collection of the questionnaires, as well as the informative sessions, have been carried out by the author of the study. Principal of the schools gave permission to offer the seminar without compromising the operation of the school curriculum. The data collection was performed in conjunction with the method of recording information by the participants. Prior to the completion of the questionnaire, the written consent of the parents and guardians was obtained, after explaining the purpose and process of the research study, which allowed the voluntary participation of young students in the research.

\section{Data Statistics}


The IBM SPSS (Statistical Package for the Social Sciences) 20.0 statistical program, acquired by IBM, was used to analyze the sample data. Using the descriptive methods, we analyzed the sample by taking measurements of the frequency of responses to all questions. Through this process we received information about demographic characteristics, awareness about the HPV and its vaccination, as well as the willingness or unwillingness of participants to be vaccinated against the HPV.

Pearson $\mathrm{X}^{2}$ statistical test, evaluated the possible dependence between questionnaire variables and students' knowledge status and behavior towards the HPV. The results between the three phases of the study were compared, both with the analysis of the tables obtained from the extraction of descriptive measures, and with the use of the statistical Paired $t$ - test for dependent samples, in the $95 \%$ confidence interval. Through these we received the necessary information to enhance students' awareness and behavior about the HPV and the vaccination against cervical cancer. Statistically significant was considered the sample with $p$ - value $=0.005$.

\section{Results}

\section{General characteristics}

A number of 434 students who met the criteria for participation in the study, filled the questionnaire, 289 (66.6\%) of which were girls and 145 (33.4\%) were boys. The vast majority of participants (95.6\%) were of Greek nationality. $3 \%$ were Albanian, while only $1.4 \%$ of the participants were of another nationality. Similarly, almost all of the participants (97.2\%) were Orthodox Christians, $0.9 \%$ were Catholics, while $1.8 \%$ were of another religion. Of the 434 students surveyed, regarding their place of residence, $181(41.7 \%)$ were living in a large city, $185(42.6 \%)$ in a small town and the remaining $68(15.7 \%)$ had a permanent residence in a village. Regarding the marital status of the parents of the participants, the vast majority of the sample (94.9\%) indicated that their parents were married.12.2\% of the sample had a low monthly family income, while $64.7 \%$ of the participants stated that the monthly family income was medium and the remaining $90(22.8 \%)$ responded that the monthly family income was high. Overall, the general demographic characteristics of the study population are summarized in Table 3. 
Table 3

General characteristics of the sample under study $(n=434)$. All variables are presented as absolute values and percentages

\begin{tabular}{|c|c|c|}
\hline Demographic characteristics & Total Sample $(n=434)$ & Percentage (\%) \\
\hline Gender & 145 & $33.4 \%$ \\
\hline Male & 289 & $66.6 \%$ \\
\hline \multicolumn{3}{|l|}{ Female } \\
\hline Place of residence & 181 & $41.7 \%$ \\
\hline Big City & 185 & $42.6 \%$ \\
\hline Small Town & 68 & $15.7 \%$ \\
\hline \multicolumn{3}{|l|}{ Village } \\
\hline Nationality & 415 & $95.6 \%$ \\
\hline Greek & 13 & $3 \%$ \\
\hline Albanian & 4 & $1.4 \%$ \\
\hline \multicolumn{3}{|l|}{ Other } \\
\hline Religion & 422 & $97.2 \%$ \\
\hline Christian Orthodox & 4 & $0.9 \%$ \\
\hline Catholic & 8 & $1.8 \%$ \\
\hline \multicolumn{3}{|l|}{ Other } \\
\hline Parental Marital Status & 412 & $94.9 \%$ \\
\hline Married & 22 & $5.1 \%$ \\
\hline \multicolumn{3}{|l|}{ Divorced } \\
\hline Monthly Family Income & 90 & $22.8 \%$ \\
\hline High & 292 & $64.7 \%$ \\
\hline Medium & 52 & $12.2 \%$ \\
\hline \multicolumn{3}{|l|}{ Low } \\
\hline Annual Family Income & 99 & $22.8 \%$ \\
\hline High & 282 & $64.9 \%$ \\
\hline Medium & 53 & $12.2 \%$ \\
\hline Low & & \\
\hline
\end{tabular}


In the main part of our research study we analyzed the data only from the students of the schools in which the informative actions took place - intervention schools $(n=248)$. In the studied interventional population, a number of two informative seminars have been carried out, which followed the first grant of the questionnaire. In this process, we tried to assess whether Health Education through informative interactive intervention in the school community, influenced the young adolescent students' knowledge about the HPV and their views on whether or not they were willing to accept a vaccination against the cervical cancer.

\section{Knowledge about HPV}

The analysis of the data revealed that no statistically significant difference was observed in the level of knowledge about the HPV, based on the sex of the participants ("I Don't Know" - Male 40.7\%, Female $46.5 \%, p=0.466)$. On the other hand, a statistically significant difference was observed between the levels of students' annual family income ("I Don't Know" - High 18.6\%, Medium 40.4\%, Low 93\%, p = 0.00), their nationality ("I Don't Know" - Greek 43.3\%, Albanian $0 \%$, Another $100 \%, p=0.00$ ) and the different residential areas of the participants ("I Don't Know" - Big City 48.5\%, Small Town 16.9\%, Village 84.6\%, p= 0.00).Typically, students who stated that they come from high-income families, have higher rates of knowledge about the HPV. Similarly, increased levels of knowledge about the virus were noticed among participants of Greek origin, compared to Albanians or other nationalities, as well as in those living in urban centers compared to those living in villages (Table 4). 
Table 4

Level of knowledge about HPV according the demographic characteristics of the sample $(\mathrm{n}=248)$.

\begin{tabular}{|c|c|c|c|}
\hline \multirow[t]{2}{*}{ Demographic characteristics } & \multicolumn{3}{|c|}{ Level of Knowledge about HPV } \\
\hline & $\mathrm{n}(\%)$ & "I do not know" n (\%) & $\chi^{2}$ test \\
\hline Total & 248 & & \\
\hline Gender & $91(36.7 \%)$ & $37(40.7 \%)$ & $p=0.466$ \\
\hline Male & $157(63.3 \%)$ & $73(46.5 \%)$ & \\
\hline \multicolumn{4}{|l|}{ Female } \\
\hline Annual Income & $59(23.8 \%)$ & $11(18.6 \%)$ & $p=0.00$ \\
\hline High & $146(58.9 \%)$ & $59(40.4 \%)$ & \\
\hline Medium & $43(17.3 \%)$ & $40(93 \%)$ & \\
\hline \multicolumn{4}{|l|}{ Low } \\
\hline Nationality & $240(96.8 \%)$ & $104(43.3 \%)$ & $p=0.00$ \\
\hline Greek & $2(0.8 \%)$ & $0(0.00 \%)$ & \\
\hline Albanian & $6(2.4 \%)$ & $6(100 \%)$ & \\
\hline \multicolumn{4}{|l|}{ Other } \\
\hline Place of Residence & $132(53.2 \%)$ & $64(48.5 \%)$ & $p=0.00$ \\
\hline Big City & $77(31.0 \%)$ & $13(16.9 \%)$ & \\
\hline Small Town & $39(15.7 \%)$ & $33(84.6 \%)$ & \\
\hline Village & & & \\
\hline
\end{tabular}

\section{Willingness for HPV vaccination}

Analysis of the data of our research (Table 5) showed that there is a statistically significant difference in the rates of vaccination willingness against HPV, based on gender ("Willing" - Male 62.6\%, Female 75.8\%, $p=0.028$ ), the annual family income ("Willing" - High 78\%, Medium 82.2\%, Low 23.3\%, $p=0.00$ ) and the place of residence ("Willing" - Big City $76.5 \%$, Small Town $80.5 \%$, Village 33.3\%, $p=0.00$ ). It is worth noting that a much higher rate of willingness to vaccinate was observed among girls than boys. At the same time, students who stated that they come from high - income families, are more likely to be vaccinated, as well as students living in - urban areas, where the rate is statistically significantly higher compared to the ones coming from rural areas. No statistically significant difference was observed in the willingness rates for vaccination based on the nationality of the participants ("Willing" - Greek $70.4 \%$, Albanian $50 \%$, Another $100 \%, p=0.233$ ). 
Table 5

Willingness for HPV vaccination according the demographic characteristics of the sample $(n=248)$.

\begin{tabular}{|llll|}
\hline Demographic & \multicolumn{3}{l}{ Willingness for HPV Vaccination } \\
\cline { 2 - 4 } characteristics & $\mathbf{n}(\%)$ & "Willing”n (\%) & $\chi^{2}$ test \\
\hline Total & 248 & & \\
\hline Gender & $91(36.7 \%)$ & $57(62.6 \%)$ & $\mathrm{p}=0.028$ \\
Male & $157(63.3 \%)$ & $119(75.8 \%)$ & \\
Female & & & \\
\hline Annual Income & $59(23.8 \%)$ & $46(78.0 \%)$ & $\mathrm{p}=0.00$ \\
High & $146(58.9 \%)$ & $120(82.2 \%)$ & \\
Medium & $43(17.3 \%)$ & $10(23.3 \%)$ & \\
Low & & & \\
\hline Nationality & $240(96.8 \%)$ & $169(70.4 \%)$ & $\mathrm{p}=0.233$ \\
Greek & $2(0.8 \%)$ & $1(50.0 \%)$ & \\
Albanian & $6(2.4 \%)$ & $6(100 \%)$ & \\
Other & & & \\
\hline Place of Residence & $132(53.2 \%)$ & $101(76.5 \%)$ & $\mathrm{p}=0.00$ \\
Big City & $77(31.0 \%)$ & $62(80.5 \%)$ & \\
Small Town & $39(15.7 \%)$ & $13(33.3 \%)$ & \\
Village & & & \\
\hline GRAPHS & & & \\
\hline
\end{tabular}

Differentiation of the level of awareness about HPV and the attitude towards vaccination (willingness or unwillingness)

According the final analysis of the results it is observed a rapid change regarding the level of knowledge about the HPV between the three phases of the study:

Phase 1: The percentage of participants who stated that "I don't know" what HPV is, was $44.4 \%(n=110)$, while $52.4 \%$ of young adolescent students $(n=130)$ replied that it was a virus. In addition, $38.3 \%(n=95)$ answered that sexual intercourse is the most common mode of transmission.

Phase 2: After the intervention, participants who stated "I don't know" what HPV is, decreased to $1.6 \%$ ( $\mathrm{n}=$ 4), while $95.6 \%(n=237)$ of those responded it was a virus. At the same time, $95.6 \%(n=237)$ of the 
participants answered that sexual intercourse is the most common mode of transmission.

Phase 3: Three months after the intervention, participants who replied "I don't know" what HPV is, had a percentage of $8.1 \%(n=20)$, while $88.3 \%(n=219)$ stated that it is a virus. Furthermore, $86.3 \%(n=214)$ of the participants indicated that the most common way of viral transmission, is the sexual intercourse (Graph 1 and Graph 2).

Moreover, a change in the responses of the studied population was noticed, regarding the willingness for HPV vaccination among young adolescent students (Fig. 3), although this rate was quite high during the first phase of the study. Specifically, in phase 1 , willing to be vaccinated was the $71 \%(n=176)$ of the sample, in phase 2 (immediately after the informative intervention) this percentage was risen to $89.1 \%$ ( $\mathrm{n}$ $=221$ ) and finally, in phase 3 (three months after the informative intervention) the willingness rate for HPV vaccination was $83.5 \%(n=207)$.

\section{Discussion}

In our study, we ecorded young adolescents' level of awareness on HPV and its vaccination, was a cornerstone for the organization, modernization and implementation of primary preventive programs, including the vaccination against cervical cancer. The vaccination against the HPV may be proven to be the best strategic option, the above reduces the risk of developing the disease in the long run, and in long term the cost effectiveness to the country's health system. In fact, vaccinating girls at a young age, before the initiation of sexual activity, is preferred nowadays mainly for 2 reasons: First of all, at that time the young body has not yet been exposed to the virus and secondly, the immune response with antibody production is much greater at younger ages [16].

\section{Sex}

According the analysis of the data of the present study, it is indicated that the level of knowledge about the HPV and the vaccination against cervical cancer, is not statistically significant between the two genders. The hypothesis that girls are more aware on this issue than boys, is confirmed in most research studies. Durosoy et al attributed the fact that the majority of participants who were informed about the effects of HPV were women, to that the awareness campaigns were aimed mainly to girls and women and less to men and boys [17]. Similarly, Gerend and Magloire noticed that female students reported higher awareness and knowledge level about the HPV and its related diseases, than their classmates [18].

Furthermore, in a recent study, Tung and his colleagues revealed that female students had a higher level of knowledge and a more positive attitude towards the HPV, than male participants [19]. Similarly, Patel and his colleagues indicated that young adolescent women were more aware of the HPV and HPV vaccination than men. This finding probably reflects the fact that HPV is mainly considered a women's health issue and that most countries currently recommend the HPV vaccination only for women [14]. However, studies have shown that homosexual male adolescents have a higher level of knowledge about 
the HPV and the effects of HPV infection than the heterosexual ones, mainly attributed to the fact that the virus is also associated with the development of anal cancer [20,21].

Regarding the vaccination against the HPV, it is noticed that girls demonstrate a higher willingness on this matter than males. The above result is confirmed by many studies from the international literature. In 2015 , Khurana and his colleagues indicated that the acceptance of cervical cancer vaccination among unvaccinated adolescent men, was much lower than in girls, emphasizing the importance of education in increasing the vaccination coverage among the male population [22]. Moreover, in a recently published systematic review, the increased acceptance of the HPV vaccines was mainly attributed to the greater willingness for vaccination against cervical cancer, by young adolescent women [23].

\section{Place of residence}

The present study revealed that the residence area of young adolescent students is strongly related to the level of knowledge about the HPV and their willingness to be vaccinated against cervical cancer. It is concluded that students living in urban centers, are more aware of the HPV and HPV vaccination than students living in rural areas. Students residing in a village tend to be unwilling to be vaccinated against cervical cancer.

The majority of scientific studies that have investigated the HPV coincide with the above expected result, reinforcing the hypothesis that the level of knowledge about the virus and its vaccination, varies not only in different countries, but also among regions of the same country. Durusoy and his colleagues concluded that there is a wide range of behavioral approaches to the intention to vaccinate against the HPV among countries, with the Western ones demonstrating higher rates of acceptance of HPV vaccines, than the Easterns. The same study also indicated that participants from Turkey's western region, were more willing to be accepted and to be included in a preventive vaccination program, than the residents of the mainland [17].

Moreover, quite significant seems to be the variation in the level of knowledge about the HPV and HPV vaccination in European countries. A higher level of awareness is observed among Italian adolescence, approximately two years after the introduction of HPV vaccines [24], while the lowest level of knowledge is noticed in Sweden, three years before the implementation of the national vaccination program [25]. Studies from Hungary and the Netherlands have also been demonstrating a higher level of awareness about the HPV, compared to Germany, suggesting that the knowledge about the virus and HPV vaccination is a multifactorial issue, the solution of which seems not to be only the introduction of a national vaccination program, against cervical cancer $[26,27,28,29,30]$.

\section{Family income}

According the results of our study, it is concluded that the annual family income is statistically significantly related to the level of knowledge about the HPV and the willingness to undergo vaccination. It is noticed that the higher the family income, the higher the level of awareness about the HPV. Typically, 
students who state that their annual family income is low, are less likely to be vaccinated against the HPV virus.

The outcome of a study conducted by Durosoy and his colleagues is similar. The authors indicated that participants with a higher socioeconomic status were more likely to be vaccinated against the HPV, than the economically weaker counterparts [17]. Similarly, Mortensen in 2010 revealed that vaccination acceptance among adolescents, was associated with a higher level of education and higher socioeconomic status of their parents, without being able to pinpoint which of the two factors was the most important [31]. In 2016, Schülein and his colleagues found that the educational level of parents, was slightly most important factor than the socioeconomic level, in terms of acceptance of HPV vaccination [32].

In contrast, a recent study from Slovenia, aiming to determine the relationship between socioeconomic factors and cervical cancer vaccination, indicated that the lowest vaccination rates were not statistically significantly correlated with the lower average family income, nor was there any relationship between higher education ratios and the immunization rate of the participants in the study [33].

\section{Family status}

The marital status of the parents of the participants in this study was not statistically significantly related to the level of knowledge about the HPV and the willingness to be vaccinated against cervical cancer. However, regardless of the marital status and the lack of correlation between the examined factors, a strong tendency to be vaccinated against the HPV among the participants was found.

Similarly, in a previous study aiming to determine whether parents would allow their children to be vaccinated against the HPV and which variables could influence their decision, the authors concluded that marital status was not related statistically significantly with the acceptance of HPV vaccination [26]. In contrast, a recent study indicated that participants' family status, along with other socio-demographic factors, such as race, nationality, maternal education, health care provider composition, family income, and the age of the unvaccinated daughter, appear to be statistically significantly related to one or more factors identified as barriers to the decision to vaccinate against cervical cancer [34].

\section{Nationality}

The analysis of the data of our study revealed that nationality is statistically significantly related to the level of knowledge about the HPV and the willingness to vaccinate. Greeks appear to be much more informed about the virus, than students of Albanian or other nationalities. However, it is necessary to point out the observed disproportion of nationalities among the participants, as $95.6 \%$ are of Greek nationality, which does not allow us to assess the result excellently and with great accuracy.

Similarly, a study from Italy indicated lower vaccination coverage rates against the HPV in foreigners, compared to Italian citizens [35]. Furthermore, other studies involving female adolescents of national minorities from degraded areas, found that the rates of HPV vaccination were lower compared to those of 
privileged ones [36, 37]. In contrast, a recent Canadian population study found that school vaccination programs can lead to higher vaccination coverage rates, even in areas inhabited by a larger percentage of national minorities [38].

\section{Health Education as a means of improving the knowledge level about the HPV and the vaccination willingness.}

In an effort to approach and interpret the main outcomes of this research study, it appears that through Health Education, using targeted informative intervention, a statistically significant increase in both the level of knowledge about the HPV and the infection caused by it, is recorded, as well as to the adolescents' willingness to be vaccinated against HPV and cervical cancer.

Furthermore, towards the same research axis and direction is the publication of a systematic bibliographic review by our research team. The conclusion we have drawn, is that adolescents are not sufficiently informed about the HPV and the HPV preventive vaccination. In order to improve the level of knowledge about the virus and the consequences of HPV infection, is mandatory to provide information through the framework of compulsory education, primary health care and the development of informative interactive interventions. The knowledge and receptive susceptibility to HPV infection and to HPV-related health issues, demonstrate the urgent need for a well-designed training program nowadays, in order to bridge the gap between HPV awareness and vaccine acceptance [39].

Previous studies have also indicated that informing young women, is an important factor in shaping positive thinking and perception towards the vaccination against HPV $[17,20,40]$. In 2014, Lee and his colleagues highlighted the role of school environment, which should provide young teens with more information about the prevention of cervical cancer, while enhancing the health education. The purpose of the above is the proper information of the students, concerning the severity of the disease, in order to be achieved higher rates of participation in a vaccination program against cervical cancer [40].

On the other hand, it has beenindicatedby other studies, that the participation and completion of a preventive HPV vaccination program is not directly correlated to the level of awareness of vaccinated women. Based on the results of other studies, it was concluded that women who were vaccinated against cervical cancer did not have a higher level of knowledge about the HPV, than the non-vaccinated ones, although it would be expected that vaccinated women would have received at least basic information on the virus and its implications [41, 42]. Similarly, Fishman and his colleagues noticed that neither parental nor adolescent HPV knowledge was related to future adolescent vaccination, as some participants with a low level of awareness about the HPV and its preventive vaccination, eventually completed the prophylactic vaccination program, whereas, in contrast, individuals who initially demonstrated high levels of knowledge, were eventually not vaccinated against HPV and cervical cancer [43].

\section{Conclusions}


Young adolescent students are poorly informed about the HPV and HPV vaccination, which can be a significant obstacle to the necessary increase in the vaccination coverage of the population. The use of interactive lecturing interventions to young adolescent students in the school environment, could contribute statistically significantly to the increase in both the level of knowledge about the HPV and the infection caused by it, as well as in the willingness of participants to be vaccinated against the HPV and cervical cancer.

At the same time, the implementation of Health Education programs in schools, under the responsibility of the State, can be an important measure in an effort to reduce the incidence of cervical cancer. Sex education of young girls and boys in order to gain a good amount of knowledge concerning issues such as sex life, family planning, proper use and effectiveness of contraceptive methods and good hygiene, reduces the exposure of the population to predisposing risk factors for developing HPV.

\section{Abbreviations}

ECDC

European Centre for Disease Prevention and Control

\section{IBM SPSS}

Statistical Package for the Social Sciences

HPV

Human Papillomavirus

WHO

World Health Organization

\section{Declarations}

\section{Ethics approval and consent to participate}

The study was approved by the Institute of Educational Policy of the Ministry of Education, Research and Religions $(219048 / \Delta 2 / 19-12-2018)$ and after the information and the consent of the Directorate of Secondary Education of the Prefecture of Trikala and the Directorate of each school complex. The aim of the study was explained to the parents - guardians of the minor students, who were asked for the signed consent, in order for the students to participate in the study. The study participants were informed that they are free to participate. The collected data were kept confidential in compliance to established Human Subject Protection guidelines.

\section{Consent for publication}

Not applicable. 


\section{Availability of data and material}

All data generated during this study are included in this manuscript.

\section{Competing interests}

The authors declare that they have no competing interests.

\section{Funding}

Not applicable.

\section{Authors' contributions}

IT conceptualized the problem, conducted statistical analyses, reviewed the literature, and drafted the manuscript. PG participated in problem refinement, design and statistical analyses of the manuscripts. GL and DP critically reviewed the manuscript for intellectual content and advised on the structure. All authors read and approved the final draft of the manuscript.

\section{Acknowledgements}

We are grateful for the participants in the study. We are also grateful to the directors and teachers of the school groups, without whose help the elaboration of the study would be very difficult.

\section{References}

1. Rerucha CM, Caro RJ, Wheeler VL. Cervical Cancer Screening. Am Fam Physician. 2018;97:441-8.

2. Jemal A, Bray F, Center MM, Ferlay J, Ward E, Forman D. Global cancer statistics. CA Cancer J Clin. 2011;61:69-90.

3. Crosbie EJ, Einstein MH, Franceschi S, Kitchener HC. Human papillomavirus and cervical cancer. Lancet. 2013;382:889-99.

4. Vu M, Yu J, Awolude OA, Chuang L. Cervical cancer worldwide. Curr Probl Cancer. 2018;42:457-65.

5. Castle PE, Maza M. Prophylactic. HPV vaccination: past, present, and future. Epidemiol Infect. 2016;144:449-68.

6. Quattrone F, Canale A, Filippetti E, Tulipani A, Porretta A, Lopalco PL. Safety of HPV vaccines in the age of nonavalent vaccination. Minerva Pediatr. 2018;70:59-66.

7. European Centre for Disease Prevention and Control. (2014). HPV vaccination in EU countries: review of new evidence Available online at: https://ecdc.europa.eu/en/news-events/hpv-vaccination-eucountries-review-new-evidence. 
8. Dorleans F, Giambi C, Dematte L, Cotter S, Stefanoff P, Mereckiene J, O'Flanagan D, Lopalco PL, D'Ancona F, Levy - Bruhl D, VENICE 2 project gatekeepers group. The current state of introduction of human papillomavirus vaccination into national immunisation schedules in Europe: first results of the VENICE2 2010 survey. Euro Surveill. 2010;15:19730.

9. Lefèvre H, Moro MR, Lachal J. The New HPV Vaccination Policy in France. N Engl J Med. 2018;378:1160.

10. Mammas IN, Theodoridou M, Koutsaftiki C, Bertsias G, Sourvinos G, Spandidos DA. Vaccination against Human Papillomavirus in relation to Financial Crisis: The "Evaluation and Education of Greek Female Adolescents on Human Papillomaviruses' Prevention Strategies" ELEFTHERIA Study. J Pediatr Adolesc Gynecol. 2016;29:362-6.

11. WHO. Comprehensive cervical cancer prevention and control: a healthier future for girls and women. Available:

http://www.who.int/immunization/hpv/learn/comprehensive_cervical_cancer_who_2013.pdf.

12. Marlow LA, Zimet GD, McCaffery KJ, Ostini R, Waller J. Knowledge of human papillomavirus (HPV) and HPV vaccination: an international comparison. Vaccine. 2013;31:763-9.

13. Bowyer HL, Marlow LA, Hibbitts S, Pollock KG, Waller J. Knowledge and awareness of HPV and the HPV vaccine among young women in the first routinely vaccinated cohort in England. Vaccine. 2013;31:1051-6.

14. Patel H, Jeve YB, Sherman SM, Moss EL. Knowledge of human papillomavirus and the human papillomavirus vaccine in European adolescents: a systematic review. Sex Transm Infect. 2016;92:474-9.

15. Yu Y, Xu M, Sun J, Li R, Li M, Wang J, Zhang D, Xu A. Human Papillomavirus Infection and Vaccination: Awareness and Knowledge of HPV and Acceptability of HPV Vaccine among Mothers of Teenage Daughters in Weihai, Shandong, China. PLoS One. 2016;11:e0146741.

16. Zhang SK, Pan XF, Wang SM, Yang CX, Gao XH, Wang ZZ, Li M, Ren ZF, Zhao FH, Qiao YL. Perceptions and acceptability of HPV vaccination among parents of young adolescents: a multicenter national survey in China. Vaccine. 2013;31:3244-9.

17. Durusoy R, Yamazhan M, Taşbakan MI, Ergin I, Aysin M, Pullukçu H, Yamazhan T. HPV vaccine awareness and willingness of first - year students entering university in Western Turkey. Asian Pac $J$ Cancer Prev. 2010;11:1695-701.

18. Gerend MA, Magloire ZF. Awareness, knowledge, and beliefs about human papillomavirus in a racially diverse sample of young adults. J Adolesc Health. 2008;42:237-742.

19. Tung WC, Lu M, Qiu X, Ervin S. Human papillomavirus knowledge, attitudes, and vaccination among Chinese college students in the United States. Vaccine. 2019;37:3199-204.

20. Gutierrez B Jr, Leung A, Jones KT, Smith P, Silverman R, Frank I, Leader AE. Acceptability of the human papillomavirus vaccine among urban adolescent males. Am J Mens Health. 2013;7:27-36.

21. Nadarzynski T, Smith H, Richardson D, Bremner S, Llewellyn C. Men who have sex with men who do not access sexual health clinics nor disclose sexual orientation are unlikely to receive the HPV 
vaccine in the UK. Vaccine. 2018;36:5065-70.

22. Khurana S, Sipsma HL, Caskey RN. HPV vaccine acceptance among adolescent males and their parents in two suburban pediatric practices. Vaccine. 2015;33:1620-4.

23. da Silva LEL, de Oliveira MLC, Galato D. Human papillomavirus vaccine receptivity: a systematic review Receptividad con respecto a la vacuna contra el virus del papiloma humano: revisión sistemática. Rev Panam Salud Publica. 2019;43:e22.

24. King LA, Lévy - Bruhl D, O'Flanagan D, Bacci S, Lopalco PL, Kudjawu Y, Salmaso S, VENICE Country Specific Gate Keepers and Contact Points. Introduction of human papillomavirus (HPV) vaccination into national immunisation schedules in Europe: Results of the VENICE 2007 survey. Euro Surveill. 2008;13:18954.

25. Tegnell A, Dillner J, Andrae B. Introduction of human papillomavirus (HPV) vaccination in Sweden. Euro Surveill. 2009;14:19119.

26. Lenselink CH, Schmeink CE, Melchers WJ, Massuger LF, Hendriks JC, van Hamont D, Bekkers RL. Young adults and acceptance of the human papillomavirus vaccine. Public Health. 2008;122:1295301.

27. Marek E, Dergez T, Rebek - Nagy G, Kricskovics A, Kovacs K, Bozsa S, Kiss I, Ember I, Gocze P. Adolescents' awareness of HPV infections and attitudes towards HPV vaccination 3 years following the introduction of the HPV vaccine in Hungary. Vaccine. 2011;29:8591-8.

28. Schmeink CE, Gosens KC, Melchers WJ, Massuger LF, Bekkers RL. Young adults awareness of HPV and vaccine acceptance after introduction of the HPV vaccine in the Dutch national vaccination program. Eur J Gynaecol Oncol. 2011;32:481-6.

29. Markowitz LE, Tsu V, Deeks SL, Cubie H, Wang SA, Vicari AS, Brotherton JM. Human papillomavirus vaccine introduction - the first five years. Vaccine. 2012;30:F139-48.

30. Samkange - Zeeb F, Mikolajczyk RT, Zeeb H. Awareness and knowledge of sexually transmitted diseases among secondary school students in two German cities. J Community Health. 2013;38:293-300.

31. Mortensen GL. Drivers and barriers to acceptance of human - papillomavirus vaccination among young women: a qualitative and quantitative study. BMC Public Health. 2010;10:68.

32. Schülein S, Taylor KJ, König J, Claus M, Blettner M, Klug SJ. Factors influencing uptake of HPV vaccination among girls in Germany. BMC Public Health. 2016;16:995.

33. Gardadolnik U, Sočan M. The Impact of Socio - Economic Determinants on the Vaccination Rates with Rotavirus and Human Papiloma Virus Vaccine. Zdr Varst. 2015;55:43-52.

34. Cheruvu VK, Bhatta MP, Drinkard LN. Factors associated with parental reasons for "no - intent" to vaccinate female adolescents with human papillomavirus vaccine: National Immunization Survey Teen 2008-2012. BMC Pediatr. 2017;17:52.

35. Venturelli F, Baldacchini F, Campari C, Perilli C, Pascucci MG, Finarelli AC, Moscara L, Rossi PG. Association between mothers' screening uptake and daughters' HPV vaccination: a quasi experimental study on the effect of an active invitation campaign. BMJ Open. 2017;7:e016189. 
36. Sacks RJ, Copas AJ, Wilkinson DM, Robinson AJ. Uptake of the HPV vaccination programme in England: a cross - sectional survey of young women attending sexual health services. Sex Transm Infect. 2014;90:315-21.

37. Tanton C, Soldan K, Beddows S, Mercer CH, Waller J, Field N, Clifton S, Copas AJ, Panwar K, Manyenga P, da Silva F, Wellings K, Ison CA, Johnson AM, Sonnenberg P. High - Risk Human Papillomavirus (HPV) Infection and Cervical Cancer Prevention in Britain: Evidence of Differential Uptake of Interventions from a Probability Survey. Cancer Epidemiol Biomarkers Prev. 2015;24:84253.

38. Drolet M, Deeks SL, Kliewer E, Musto G, Lambert P, Brisson M. Can high overall human papillomavirus vaccination coverage hide sociodemographic inequalities? An ecological analysis in Canada. Vaccine. 2016;34:1874-80.

39. Thanasas I, Lavranos G, Gkogkou P, Paraskevis D. Understanding of Young Adolescents About HPV Infection: How Health Education Can Improve Vaccination Rate. J Cancer Educ. 2020 Jan 11. doi: 10.1007/s13187-019-01681-5.

40. Lee $A$, Ho M, Cheung CK, Keung VM. Factors influencing adolescent girls' decision in initiation for human papillomavirus vaccination: a cross - sectional study in Hong Kong. BMC Public Health. 2014;14:925.

41. Blödt S, Holmberg C, Müller - Nordhorn J, Rieckmann N. Human Papillomavirus awareness, knowledge and vaccine acceptance: a survey among 18-25 year old male and female vocational school students in Berlin, Germany. Eur J Public Health. 2011;22:808-13.

42. Napolitano F, Napolitano P, Liguori G, Angelillo IF. Human papillomavirus infection and vaccination: Knowledge and attitudes among young males in Italy. Hum Vaccin Immunother. 2016;12:1504-10.

43. Fishman J, Taylor L, Kooker P, Frank I. Parent and adolescent knowledge of HPV and subsequent vaccination. Pediatrics. 2014;134:e1049-56.

\section{Figures}




\section{"What is HPV ?"}

120

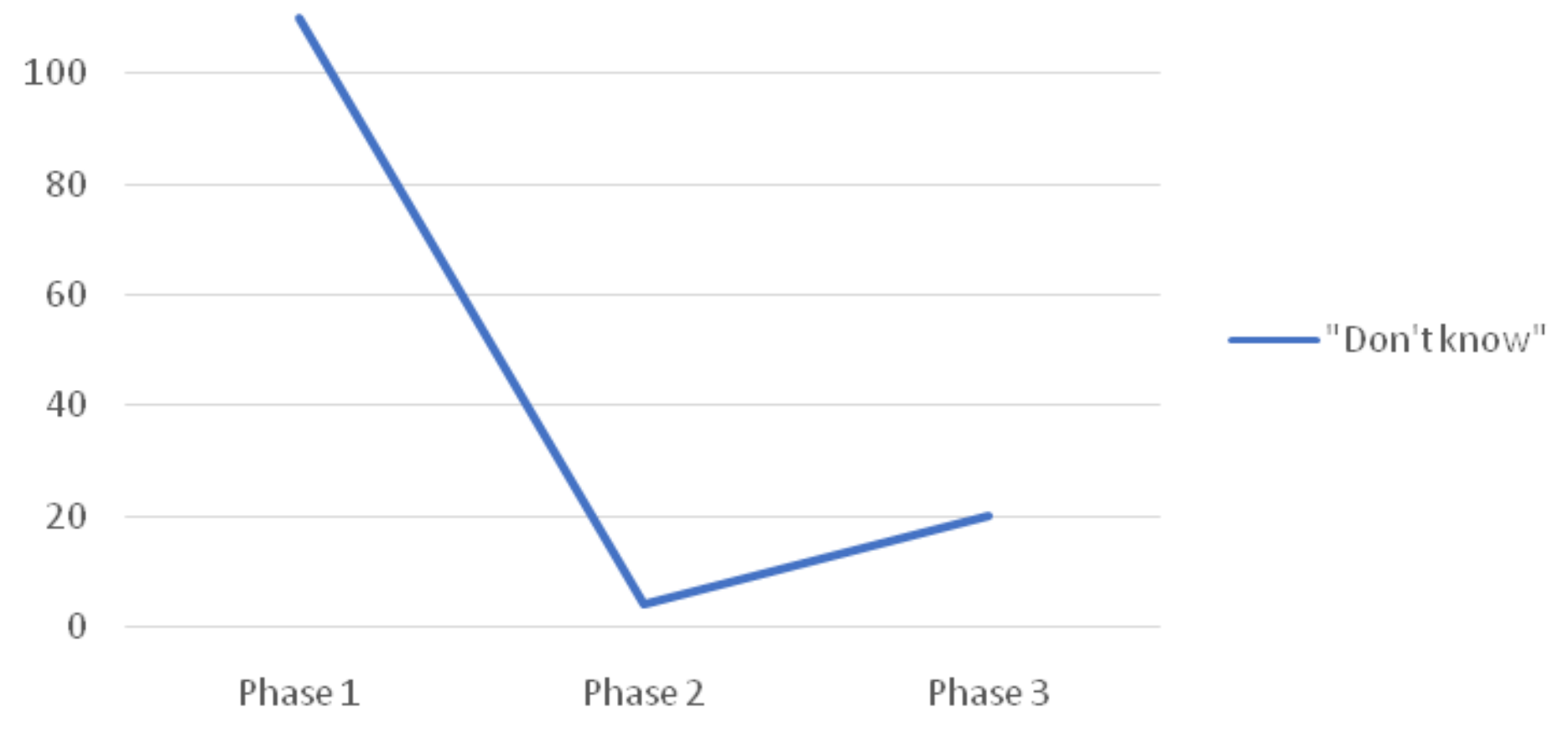

\section{Figure 1}

Graphic illustration of the level of knowledge about HPV, based on the question "What is HPV» throughout the research study. 


\section{"What are the most common routes of HPV transmission?"}

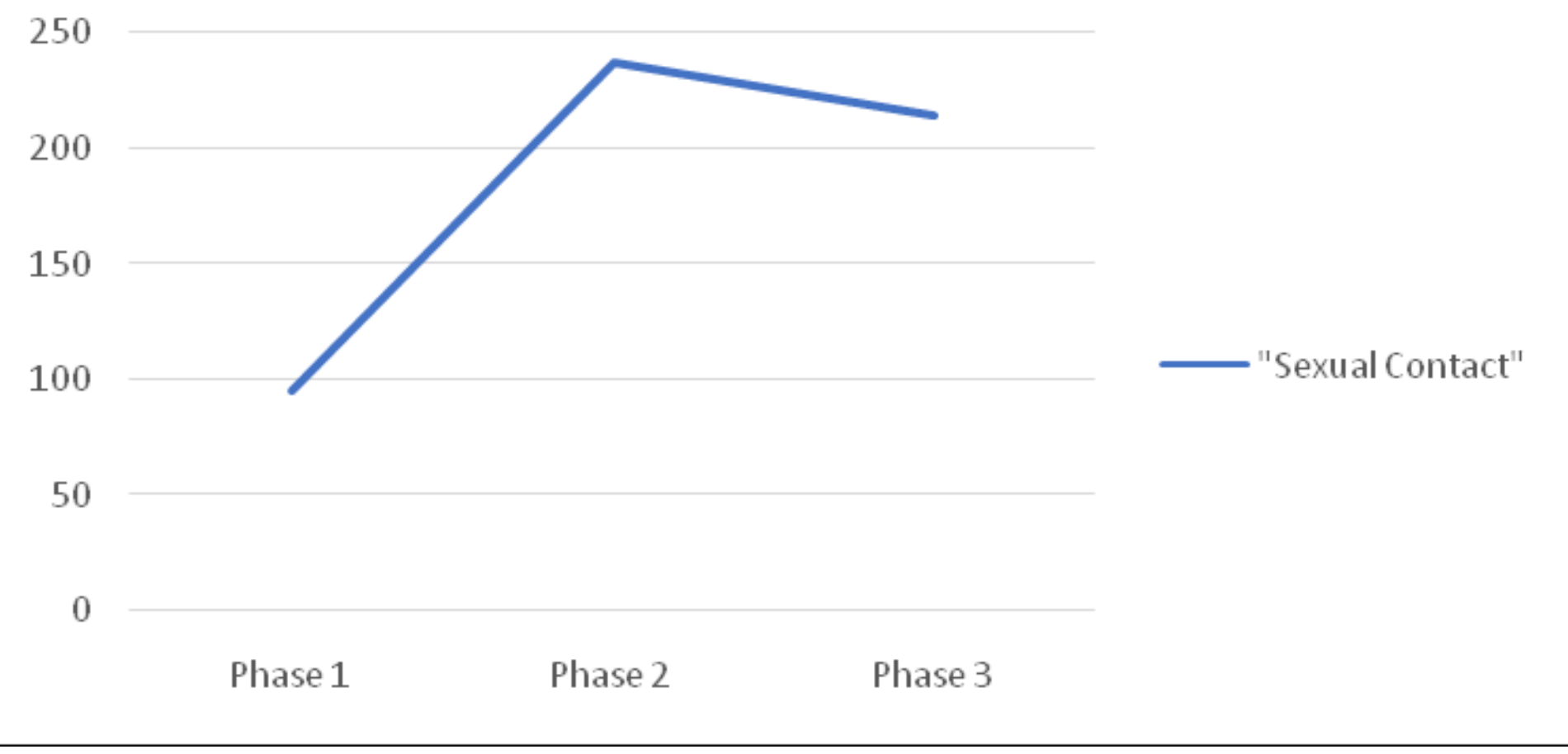

\section{Figure 2}

Graphic illustration of the level of knowledge about HPV, based on the question «What are the most common routes of HPV transmission», throughout the research study. 


\section{"Are you available to vaccinate yourself if you are getting the HPV vaccine for free ? "}

250

200

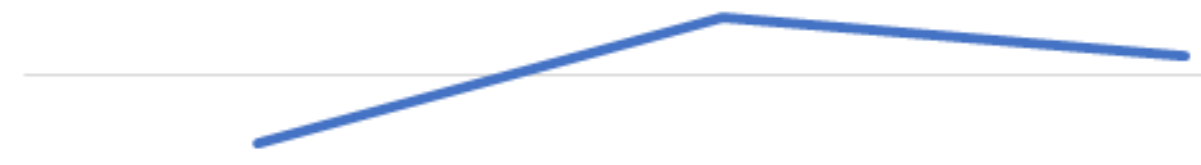

150

100

50

0

Phase 1

Phase 2

Phase 3

Figure 3

Graphic illustration of the young students' willingness for vaccination against HPV, based on the question «Are you willing to undergo vaccination» throughout the research study 